Supplement of Geosci. Model Dev., 14, 2029-2039, 2021

https://doi.org/10.5194/gmd-14-2029-2021-supplement

(C) Author(s) 2021. CC BY 4.0 License.

(c) (i)

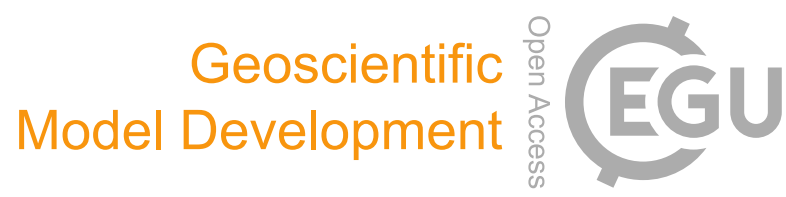

Supplement of

\title{
How to reconstruct aerosol-induced diffuse radiation scenario for simulating GPP in land surface models? An evaluation of reconstruction methods with ORCHIDEE_DFv1.0_DFforc
}

Yuan Zhang et al.

Correspondence to: Yuan Zhang (yuan.zhang@1md.jussieu.fr)

The copyright of individual parts of the supplement might differ from the article licence. 

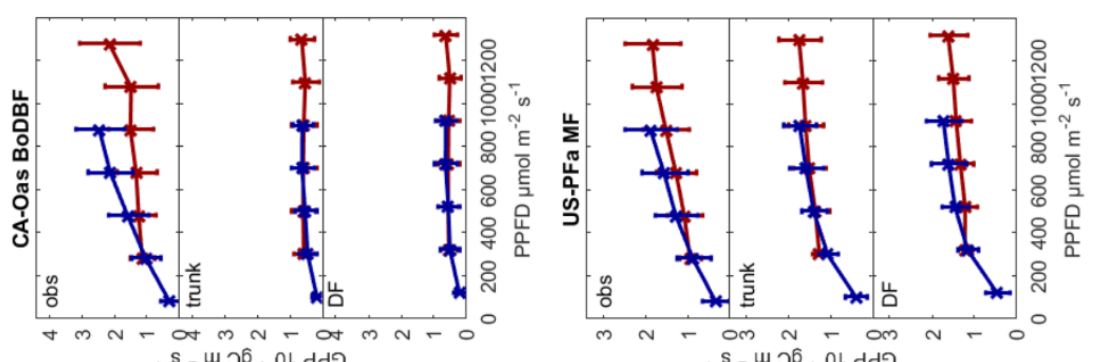

䒿
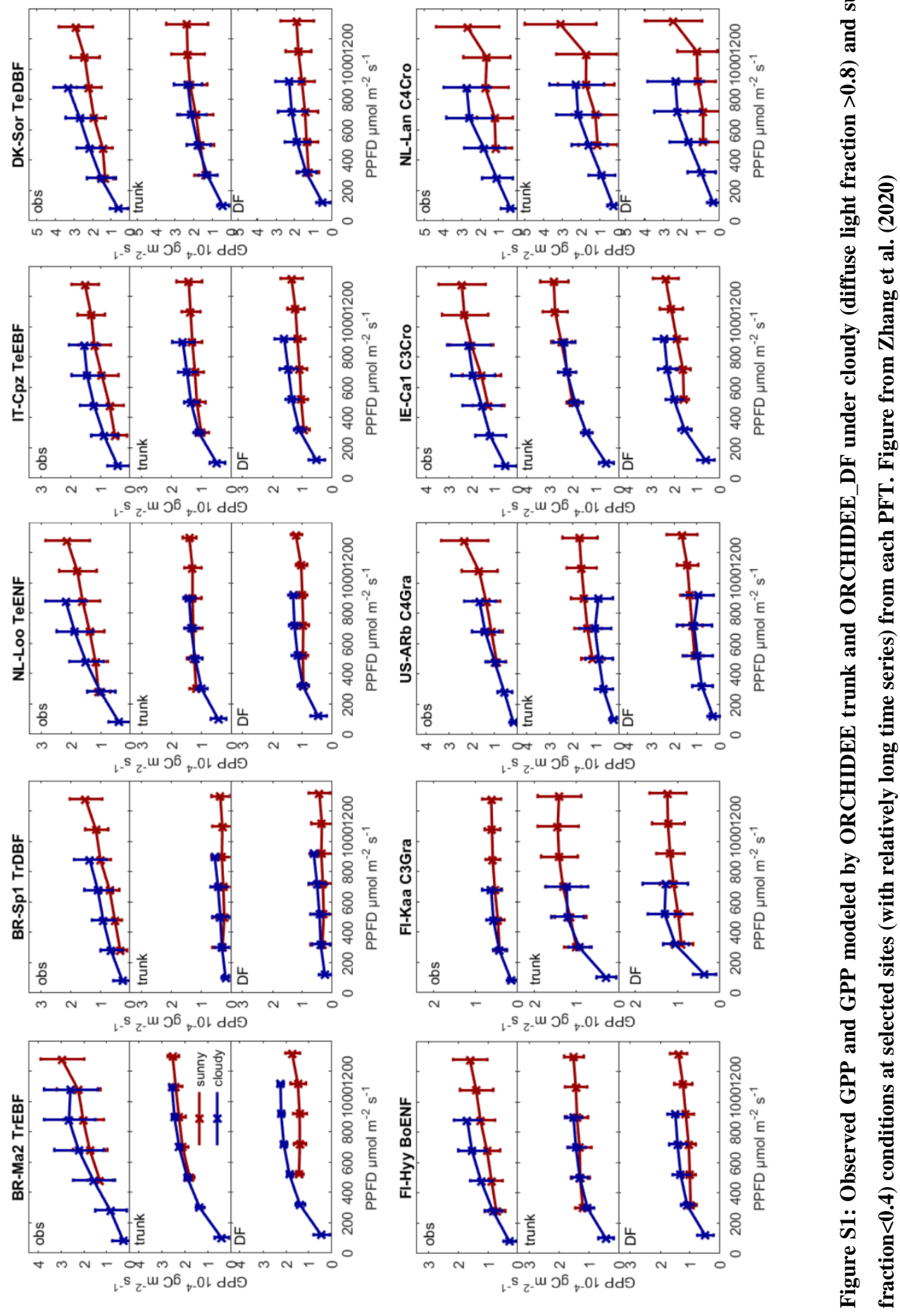

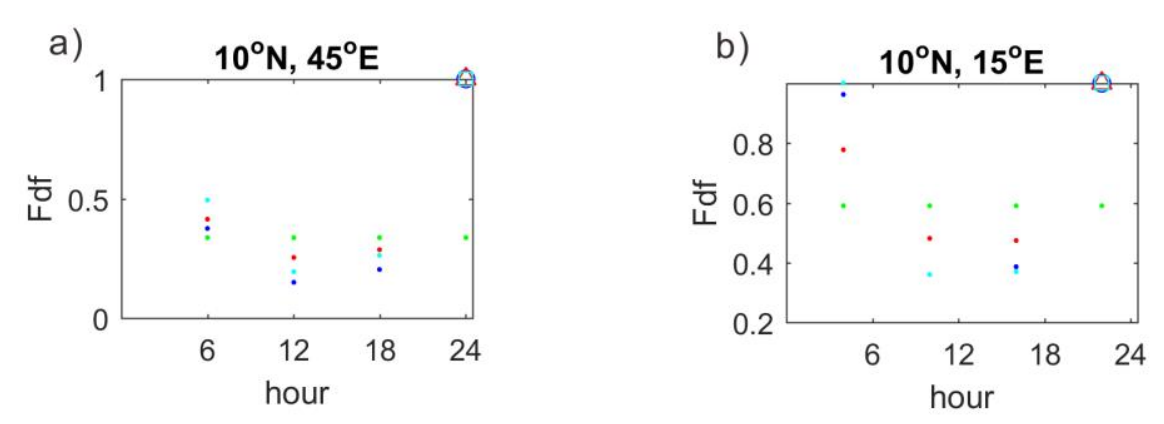

c)

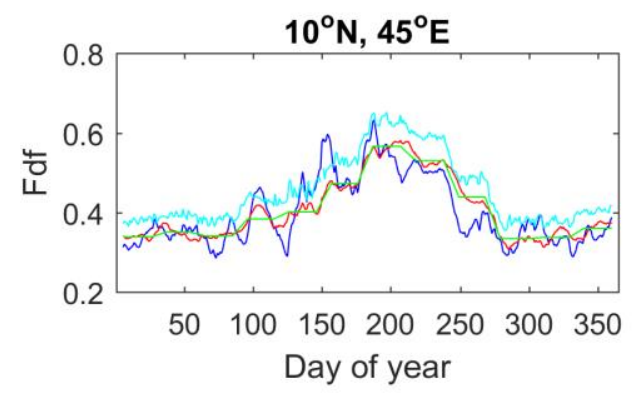

d)
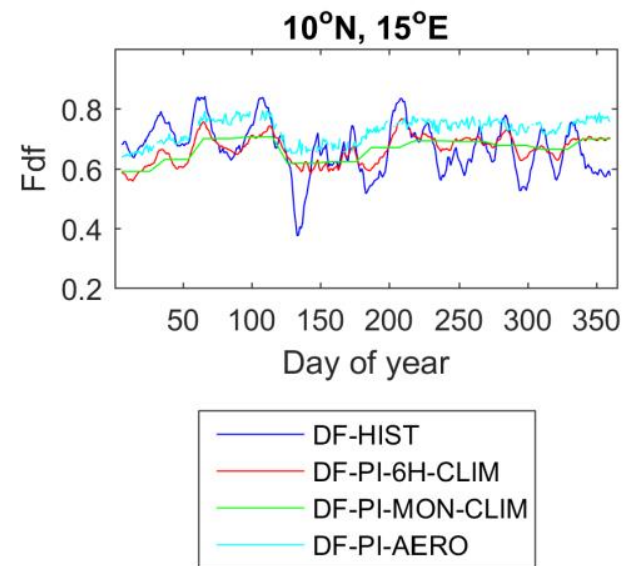

Figure S2. The diurnal cycle of Fdf on 1901-01-01 (a) and (b), and the seasonal cycle of Fdf in 1901 (c) and (d) in different reconstructions at selected grids. The open markers in (a) and (b) are night time values filled with 1 . 

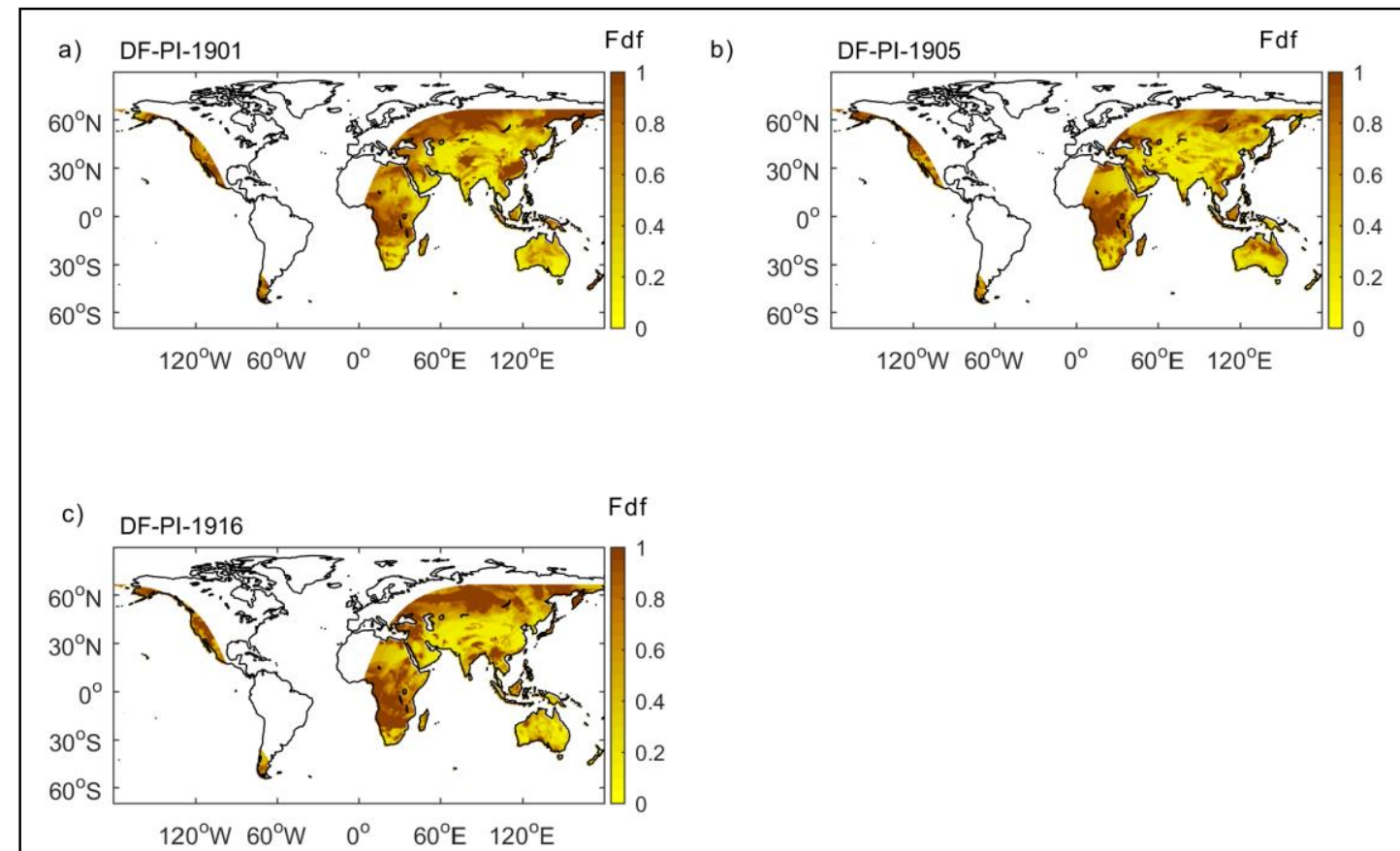

Figure S3. Same as Fig 1 but for DF-PI-1901, DF-PI-1905 and DF-PI-1916 